Return to the Manage Active Submissions page at http://spie.org/app/submissions/tasks.aspx and approve or disapprove this submission. Your manuscript will not be published without this approval. Please contact author_help@spie.org with any questions or concerns.

\title{
Deformation monitoring in prestessing tendons using fibre Bragg gratings encapsulated in metallic packages
}

\author{
Grzegorz Fusiek*a $^{\text {a }}$, Marcus Perry ${ }^{\mathrm{a}}$, Paweł Niewczas ${ }^{\mathrm{a}}$, Michael Johnston ${ }^{\mathrm{b}}$ \\ ${ }^{a}$ Institute for Energy and Environment, Department of Electronic and Electrical Engineering, \\ University of Strathclyde, Glasgow G1 1XW, United Kingdom; ${ }^{b}$ Civil Design Group, EDF Energy, \\ Nuclear Generation, East Kilbride G74 5PG, United Kingdom
}

\begin{abstract}
An investigation into the capability of deformation monitoring using fibre Bragg gratings encapsulated in metallic packages is presented in the paper. The proposed approach relies on a grating inscription into a metal coated fibre and brazing the fibre into a metal capillary using induction heating. A metal rod instrumented with encapsulated FBG strain and temperature sensors is placed in an electromechanical tester and stressed up $80 \%$ of its ultimate tensile strength. It is demonstrated through a $60 \mathrm{~h}$ experiment that the sensors are capable of real-time deformation monitoring.
\end{abstract}

Key words: optical fibre bonding and sealing, induction heating, sensor encapsulation, deformation monitoring.

\section{INTRODUCTION}

The use of fibre Bragg grating (FBG) sensors for structural health monitoring (SHM) has been researched for years. Stress, strain, or force measurement systems employing FBGs have been proposed for aerospace ${ }^{1-3}$, nuclear fission and fusion reactors ${ }^{4-7}$, or bridge and concrete monitoring ${ }^{8-11}$ applications. It is clear that in all these applications the sensor attachment must ensure long-term reliability even at adverse environmental conditions. Since the sensor exposure to high temperature, high strain or high dosage of nuclear radiation may lead to the degradation of the fibre and/or the grating structure $^{12,13}$, appropriate sensor packaging and attachment are crucial for its operation and lifetime.

To overcome the limitations of conventional epoxy-based FBG bonding and attachment methods, we previously developed a metal coated fibre sealing and bonding technique based on induction heating. The resultant joints performance was proven at high temperature $\left(350^{\circ} \mathrm{C}\right)$ and high pressure $(15 \mathrm{kpsi})$ conditions $\mathrm{s}^{14,15}$. We also showed experimentally that by selecting proper materials, such as kovar, brazing standard FBGs into metallic ferrules can be possible without any significant deterioration in the grating reflection ${ }^{16}$. Our recent work related to the high stress monitoring of prestressing tendons ${ }^{17}$ employing the developed technology demonstrated an improved performance over the epoxy-based strain monitoring systems ${ }^{17,18}$. In this paper, a method of fibre Bragg grating encapsulation into metallic packages based on induction brazing and sensor attachment to a metal rod to measure high strain are proposed and investigated.

\section{SENSOR ENCAPSULATION}

A schematic diagram of an FBG strain sensor encapsulated in a metal capillary is shown in Figure 1. A previously developed optical fibre sealing and bonding technique employing induction heating was utilised to join the sensor components ${ }^{14}$. Firstly, a single-mode copper coated fibre was cut into meter long pieces. A $15-\mathrm{mm}$ long section of the coating was removed from the fibre by submersing it in $65 \%$ nitric acid $\left(\mathrm{HNO}_{3}\right)$. Such prepared fibres were than used for grating inscription and encapsulation. 
Return to the Manage Active Submissions page at http://spie.org/app/submissions/tasks.aspx and approve or disapprove this submission. Your manuscript will not be published without this approval. Please contact author_help@spie.org with any questions or concerns.

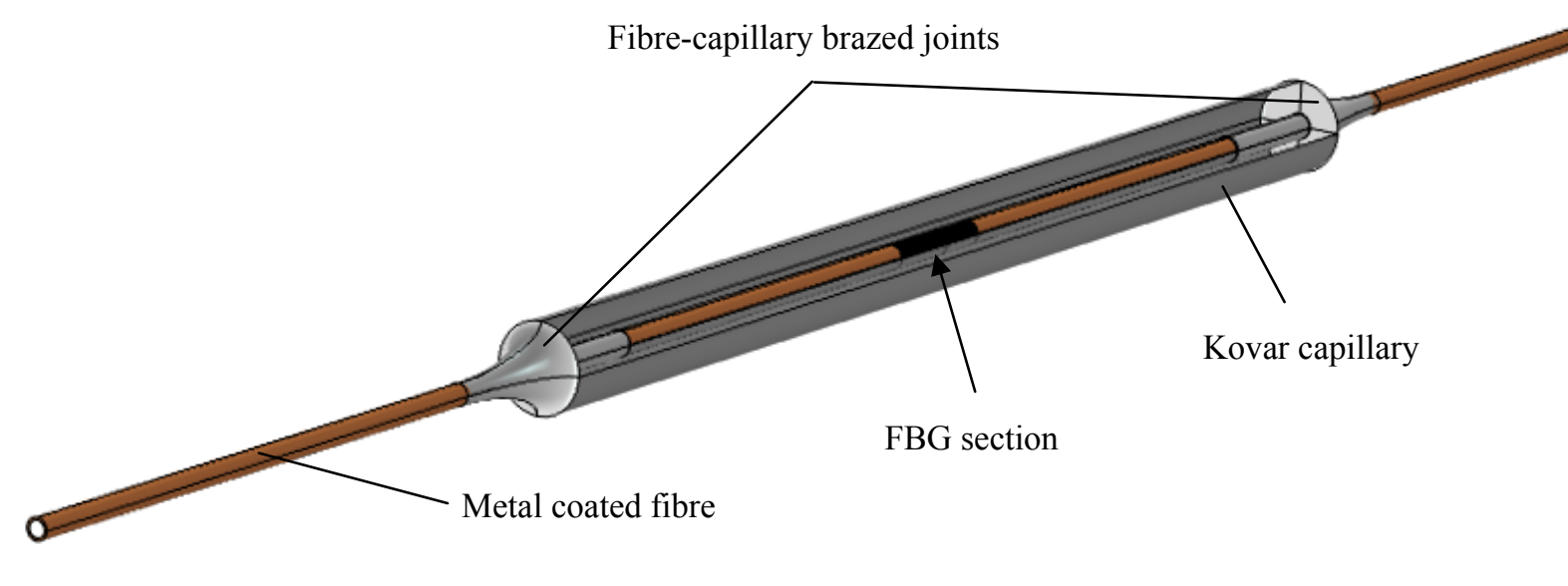

Figure 1. FBG sensor encapsulated in a metallic capillary.

The encapsulation process involved inserting a copper coated fibre with an inscribed FBG sensor into a kovar capillary, aligning the components, and brazing the fibre to the capillary using induction heating. During the joint fabrication, the capillary rested on a v-grooved ceramic bench while the fibre was held by two micro-positioning stages placed nearby both ends of the ceramic bench ${ }^{14}$. The length of the capillary was $20 \mathrm{~mm}$ and its ID/OD was $0.2 / 0.7 \mathrm{~mm}$. The fibre outside diameter was $170 \mu \mathrm{m}$. The components were appropriately aligned so that the FBG section was in the centre of the capillary (Figure 1), and the fibre and capillary did not come into contact during heat processing. A small amount of flux and silver-based brazing paste were then applied at both ends of the capillary. The melting temperature of the brazing paste was $620{ }^{\circ} \mathrm{C}$. To protect the FBG from excessive heat and deterioration, a heat susceptor was used at the joint location ${ }^{14,17}$. During the brazing process, a water cooled conductive coil was consecutively brought over each end of the capillary. To melt the paste and form the joint, a $370-\mathrm{kHz}$ current of $200 \mathrm{~A}$ was applied to the coil for $20 \mathrm{~s}$. The assembly was then cooled down naturally to room temperature.

\section{EXPERIMENTAL RESULTS}

Following the encapsulation process, the FBG strain sensor was attached to a metal rod as shown in Figure 2. The rod was a plain strand wire made of steel Y1670C having a length of $0.5 \mathrm{~m}$ and $7 \mathrm{~mm}$ diameter according to British Standard BS 5896:2012. The FBG strain sensor was brazed to $0.5-\mu \mathrm{m}$ thick metal foil strips and welded to the steel rod at both ends using an electrical resistance spot welder ${ }^{17}$.

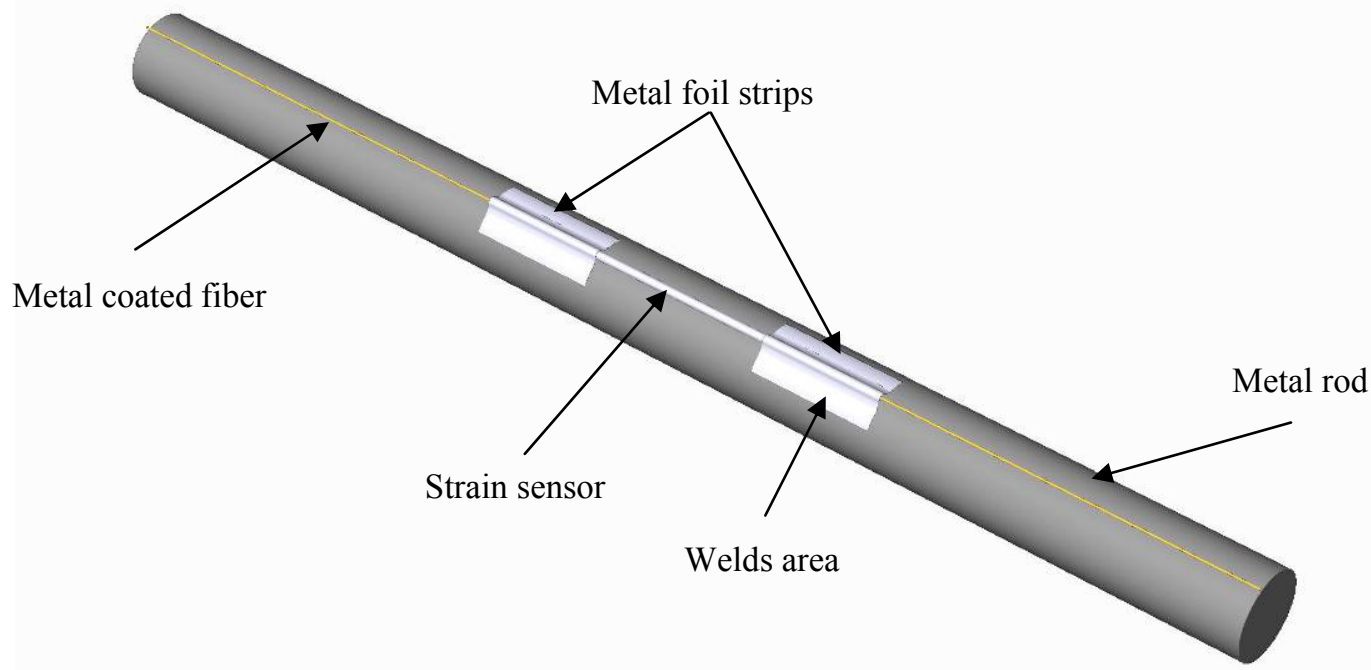

Figure 2. Diagram of an encapsulated FBG strain sensor attached to a metal rod. 
Return to the Manage Active Submissions page at http://spie.org/app/submissions/tasks.aspx and approve or disapprove this submission. Your manuscript will not be published without this approval. Please contact author_help@spie.org with any questions or concerns.

It is well known that a standard FBG sensor responds to strain and temperature simultaneously. A relative change in the FBG peak wavelength, $\Delta \lambda_{B} / \lambda_{B}$, due to a change in strain, $\Delta \varepsilon$, and temperature, $\Delta T$, can be expressed by $\Delta \lambda_{B} / \lambda_{B}=C_{\varepsilon} \cdot \Delta \varepsilon+$ $C_{T} \cdot \Delta T$, where $C_{\varepsilon}$ and $C_{T}$ are the strain and temperature sensitivities. To distinguish between strain and temperature readings, an additional FBG temperature sensor located in proximity of the FBG strain sensor was used. The FBG temperature sensor was encapsulated in the similar way as the strain sensor but welded to the rod at one end only (Figure 2). Since the temperature sensor was strain-free, it allowed strain readings to be corrected by subtracting the wavelength shift due to temperature fluctuations ${ }^{17}$.

To verify the optical sensors capability of deformation monitoring, a $60 \mathrm{~h}$ test was performed at a constant load of $50 \mathrm{kN}$ using an Instron 5969 electromechanical tester. The instrumented rod was placed in the machine and a relaxation routine was performed prior to the long-term test by stress cycling the rod up to $1300 \mathrm{MPa}(80 \%$ UTS) four times to minimize any residual stresses induced during the sensors fabrication and attachment ${ }^{17}$. Following the relaxation, the load was increased at a rate of $10 \mathrm{kN} / \mathrm{min}$ up to $50 \mathrm{kN}$ and kept constant for $60 \mathrm{~h}$. It was then decreased to $0 \mathrm{kN}$ at a rate of 10 $\mathrm{kN} / \mathrm{min}$. The FBGs having peak wavelengths of $1541 \mathrm{~nm}$ and $1564 \mathrm{~nm}$ were used for strain and temperature sensors, respectively. During the experiment, the sensors were monitored online using a Micron Optics spectral interrogation unit (sm125). The peak wavelengths of the FBG strain and temperature sensors along with the load and extensometer output from the Instron machine were recorded every half a second.

As it was previously demonstrated by the authors ${ }^{17}$, a temperature sensitivity of the strain sensor was $20 \%$ higher than the temperature sensor due to the influence of thermal expansion of the steel rod for the presented sensor encapsulation and attachment method. Therefore, the influence of the ambient temperature fluctuations on strain measurements were corrected for using the results obtained during the previous thermal characterisation of the sensors. A comparison of the results obtained during deformation monitoring over $60 \mathrm{~h}$ at a constant load are shown in Figure 3.

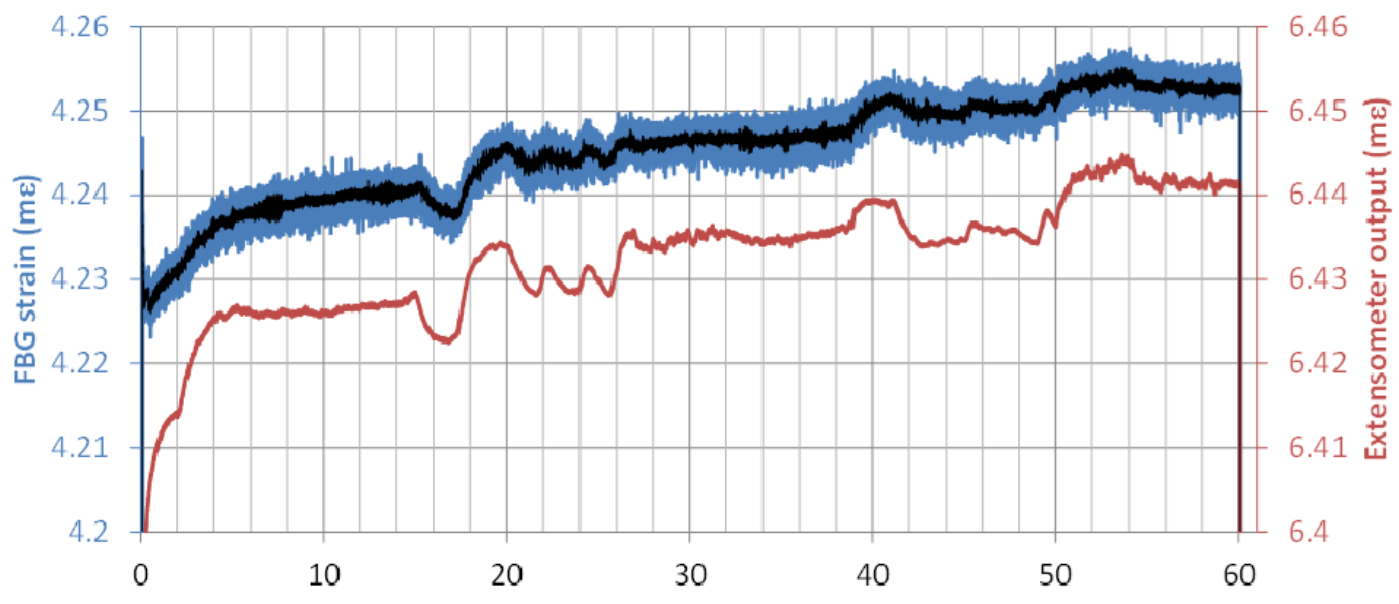

Time (hours)

Figure 3. Comparison between FBG-based strain sensor and extensometer readings. The black curve superimposed on the FBG strain signal is a moving average of 10 samples.

It is clear from the above figure that the FBG strain sensor response is in good agreement with the records obtained from the extensometer. The small fluctuations apparent in the signals are most likely a consequence of the adjustments made by the Instron control software to keep the load constant at ambient temperature fluctuations. The magnitude of these fluctuations is within the machine calibration accuracy. The strain transfer between the rod and the optical strain sensor, estimated from the data presented above, equalled to around $66 \%$ which is in good agreement with the previous results ${ }^{17}$. Based on the experimental results, it can be concluded that the sensor was capable of deformation monitoring at high load of $50 \mathrm{kN}$ equivalent to a stress of $1300 \mathrm{MPa}$, or $80 \% \mathrm{UTS}$, and thus may be a valuable tool in real-time monitoring of presterssing tendons. 
Return to the Manage Active Submissions page at http://spie.org/app/submissions/tasks.aspx and approve or disapprove this submission. Your manuscript will not be published without this approval. Please contact author_help@spie.org with any questions or concerns.

\section{CONCLUSIONS}

An investigation into the capability of deformation monitoring using fibre Bragg gratings encapsulated in metallic packages has been presented in the paper. Following gratings inscription into metal coated fibres, the sensor encapsulation was realised by brazing the fibre into a metal capillary using induction heating. Encapsulated FBG strain and temperature sensors were then attached to a metal rod, placed in an electromechanical tester, and stressed up 1300 $\mathrm{MPa}$, or $80 \%$ UTS. It has been demonstrated by a $60 \mathrm{~h}$ experiment that the sensors are capable of real-time deformation monitoring and have the potential to constitute valuable tools in the SHM instrumentation.

\section{ACKNOWLEDGEMENTS}

This work was supported by EDF Energy Nuclear Generation, Ltd.

\section{REFERENCES}

[1] Li, J., Zhou, Z., and Ou, J., "Sensors and smart structures technologies for civil, mechanical, and aerospace systems." Proc. SPIE 5765(2), 265-274 (2004b).

[2] Kahandawa, G. C., Epaarachchi, J., Wang, H., and Lau, K. T., "Use of FBG sensors for SHM in aerospace structures," Photonic Sensors 2(3), 203-214 (2012).

[3] A. Panopoulou, D. Roulias, T. H. Loutas, and V. Kostopoulos, "Health Monitoring of Aerospace Structures Using Fibre Bragg Gratings Combined with Advanced Signal Processing and Pattern Recognition Techniques," Strain 48(3), 267-277 (2012).

[4] J. R. Lee, S. Y. Chong, C. Y. Yun, and H. Sohn, "Design of Fiber Bragg Grating Acoustic Sensor for Structural Health Monitoring of Nuclear Power Plant," Adv. Mater. Res. 123-125, 859-862 (2010).

[5] Crolla, P., Niewczas, P., \& Mcdonald, J.. "An alternative method for the monitoring of strain and temperature in a nuclear fusion reactor," $44^{\text {th }}$ International Universities Power Engineering Conference, (2009)

[6] Niewczas, P., Fusiek, G., \& Crolla, P. "Concept level evaluation of the full-scale deployment of fibre bragg grating sensors for measuring forces in JET during plasma disruption events," $5^{\text {th }}$ International Conference on Condition Monitoring and Machine Failure Prevention Technologies, (2008).

[7] I.-Y. Jang and Y.-W. Yun, "Study on Stress Transfer Property for Embedded FBG Strain Sensors in Concrete Monitoring,” Int. J. Concr. Struct. Mater., 3(1), 33-37 (2009).

[8] E. Rizk, H. Marzouk, A. Hussein, and X. Gu, "Structural health monitoring of slab-column connections using FBG sensors," J. Civ. Struct. Heal. Monit. 2( 1), 17-27 (2012).

[9] Chunfeng Wan, Wan Hong, Jianxun Liu, Zhishen Wu, Zhaodong Xu, and Shu Li, "Bridge Assessment and Health Monitoring with Distributed Long-Gauge FBG Sensors," International Journal of Distributed Sensor Networks 2013, (2013).

[10] Guo-Wei Li, Cheng-Yu Hong, Jian Dai, Liang Yu, and Wan-Huan Zhou, "FBG-Based Creep Analysis of GFRP Materials Embedded in Concrete," Mathematical Problems in Engineering 2013, (2013).

[11]Perry, M., Niewczas, P., Johnston, M., "Effects of Neutron-Gamma Radiation on Fiber Bragg Grating Sensors : A Review," IEEE Sensors Journal 12, 3248-3257 (2012a).

[12] Perry, M, Niewczas, P, Johnston, M, Cook, K \& Canning, J, "Mechanical strength of silica fiber splices after exposure to extreme temperatures," OFS22, (2012)

[13] Niewczas, P., Fusiek, G., "Induction Heating Assisted Optical Fiber Bonding and Sealing Technique," OFS21, (2011)

[14] Fusiek, G., Niewczas, P., Burt, G.M., "Preliminary Evaluation of a High-Pressure, High-Temperature Downhole Optical Sensor," IEEE Sensors 2011, (2011)

[15] Perry, M., Niewczas, P., Johnston, M., Cook, K., Canning, J., "Induction Brazing of Type-I Fiber Bragg Gratings into Kovar Ferrules Exploiting Curie Transition.” IEEE Sensors Journal 13, 816-823 (2013)

[16] M. Perry, Z. Yan, Z. Sun, L. Zhang, P. Niewczas, M. Johnston, "High stress monitoring of prestressing tendons in nuclear concrete vessels using fibre-optic sensors," Nuclear Engineering and Design 268, 35-40 (2014)

[17] Li, E., Xi, J., Chicharo, J.F., Liu, T., Li, X., Jiang, J., Li, L., Wang, Y., Zhang, Y., "The Experimental evaluation of FBG sensor for strain measurement of prestressed steel strand," Proc. SPIE Smart Structures Devices and Systems II 5649, 463-469 (2004) 